\title{
"The effects of using oriented ballistic exercises according to the kinematic characteristics of the reverse body lift skill on some physical, physiological variables and the level of skill performance for junior wrestlers"
}

\section{* Dr. Mohammed Fathi Nassar Abu Al Saad \\ Introduction and research problem}

The Physical Education is one of the most important areas of life that depended in the resolution of its multiple problems on the scientific method, and wrestling sport is one of the sports that has developed and progressed thanks to following the scientific methods in the field of training in order to upgrade its various elements to reach the highest levels of competition and in order to achieve that, proper scientific planning is required for the development of the level of components contributing in the physical, skill, tactical and psychological performance of wrestlers.

All of Bastawisi Ahmed (1999 AD) and Abdul Rahman Zaher (2000 AD) indicated that planning a scientific training system properly and based on taking into account the individual differences among the players and their physical and skill abilities achieves a process of physiological adaptation affects the performance level of specialist sports activity to reach the high levels. (12: 137) (2:12)

\begin{abstract}
All of Hassan Allawi(1994 AD),Hamdi Asim(1996 AD)and Subhi Abdul Hamid (1996AD)indicated that the sportive training leads to physiological changes in all the body organs of the player in a positive way achieving the functional adjustment required to perform the physical load with high efficiency, the more his physical and physiological fitness improved, the more he will be able to use his technical skills and implement his tactical duties to the fullest extent and efficiently.(32:23)(20:28) (25: 8)
\end{abstract}

All of Scott \& Edward (1994 AD), Bastawisi Ahmad (1999AD) and Abu Ela Abdul Fattah, Nasr Radwan (2003 AD), indicated that the successful coach is the one who plans his training program to increase capacities required by the specialist activity type, using exercises that work on the energy system that the player relies on, as well as he must use the same movements of this activity so that the focus is to be on training the working and participating muscle groups to perform the specialist sports activity according to the nature of their work. $(41: 30)(12: 115)(3: 42)$

(Mussad Ali Mahmoud, 1987 AD) indicated that scientific research conducted in the field of training with weights, most of their findings have indicated that training with weights has become one of the effective means for the development of different types of muscle strength, especially for advanced wrestlers in the countries of the world (24: 248)

Ballistic training is one of the relatively modern ways as it links between the elements of training with weights and bliometric exercises using a variety of weights and high speeds, which is used to overcome the lack of speed resulting from the traditional training with weights $(32: 22)$

\footnotetext{
* Lecturer, Of competitive and Aquatic sports Department Faculty of Physical education . Sadat city university
} 
Ahmed Gouda (2009 AD) also indicated that the ballistic resistance exercises includes explosive movements against resistance by extrusion or snap weights varied at the highest possible speed.(6:56), (45)

All of Gary, Moran, George, \& Mac (1997 AD), Factors (2000 AD), Edmund (2001 AD) mentioned that ballistic training is one of the modern methods that are no less efficient and positive than the rest of the other training methods at the level of muscle strength development and overcome the lack of speed as it includes exercises of (lifting - extrusion snap) of light weights at high speeds, rising from the seat, the squat jump, press, push, swings and turnover to the fullest kinetic extent and in all directions, as well as links between the weights resistance method and the method of switching from contraction by lengthening to contraction by shortening, and it does not have a lack or low speed phase so it works to maintain the energy of movement inherent in a serious attempt to produce a quick power, where these movements, when performing them, pass through three stages, the first is the muscular contraction phase by shortening towards contraction center, the second is regression or landing phase, which depends on the amount of movement generated in the first stage, and the third is the diminishing speed stage accompanied by muscular contraction by lengthening which means going away of the contraction center. (19:32) (33:33) (14:17) (46)

All of Ahmed Farouk (2003 AD), Sharif Mahrous (2005 AD), Kenny (2005 AD) and Christian (2006 AD) refer to the possibility of the development of capacity through the use of exercises of the full range of motion against resistance (medical ball - weight - weight of the player) and training intensity varied from a low to high degree with a load degree of (30\%: 50\%) of the maximum load of the player, requiring $(20 \mathrm{sec})$ using repetition and a rest of up to ( $3 \mathrm{~min}$ ) between the groups and is used once or twice a week for a specific period of time of (4: 8 weeks), so these groups must be stopped when there is the possibility of maintaining the speed and quality of movement. $(5: 34)(42: 17)(25: 49)(13: 33)$

All of Paul \& Duane (1999 AD) mentioned that the use of biomechanical analysis is the scientific way for the development of training and performance programs where it works to improve performance and correct mistakes as well as the development of technical performance and fitness programs for the player, also it prevents the occurrence of injuries. $(41: 13)$

Eweys Al Jebali (2000 AD) indicated that analytical methods can be used to reach the details of the movement and identify the form of performance and perfect it achieving saving in the effort. (11: 65)

Essam Abdul Khaliq (2003 AD) confirmed that exercises similar in performance to the basic skills are the main method of special physical preparation and development of the right skill performance of kinetic skills and give the player the same sense required to be implement in the kinetic skill. $(17: 87)$

the reverse body lift skill is one of the most important skills of throwing backward by arching in the sport of Romanian wrestling and "Mohammad Reda Al Ruby" in (2005 AD) and Nabil Hosni Al Shorbaji in(2008 AD) referd to the importance of this skill as it is important and essential for all the wrestlers, which greatly affect the results of games, it is considered one of the major technical skills that require the highest technical points and through scoring touching shoulders. (29: 52) (30:2) 
Through researcher experience as a former player and a member of the Technical Committee for Wrestling at Menofia, he noted a lack of kinetic speed (kinetic acceleration) of throwing backward by arching skills and the existence of time interval between the stages of the implementation of the movement (holding and assembly - lifting - throwing and overthrow) which poses a risk to the attacker and gives the opportunity to the opponent to implement the defense whether to derail the hold or ascend the attacker during the implementation and control him at the dangerous situation, so the researcher is trying to use the ballistic exercises - as one of the exercises types that is characterized by the element of speed during performing it against low to medium resistances - and introducing them into throwing backward by arching skills to try to improve the kinetic speed during the performance. performing throwing backward skills by arching with the appropriate speed and kinetic ability gives the opportunity to the attacker to get the largest number of technical points at once (grand Technic), which helping him to win with the technical superiority over his opponent.

\section{- Research Objectives:}

The development of a training program using oriented ballistic exercises according to the kinematic characteristics of the reverse body lift skill with the aim to identify:

1- The impact of the training program on some physical, physiological variables under discussion among the individuals of the experimental group.

2- The impact of the training program on skill performance among the individuals of the experimental group.

\section{- Research Hypotheses:}

1- There are significant statistical differences between the (pre and post) measurements of the control group and the experimental group in on some physical, physiological variables under discussion and the level of skill performance in favor of the post measurement.

2- There are significant statistical differences between the post measurements of the control group and the experimental group in on some physical, physiological variables under discussion and the level of skill performance in favor of the experimental group.

\section{Research Terms:}

Ballistic training: it is the muscle's ability to perform explosive moves such as throwing a weight or performance at the highest possible speed against mild to moderate resistances ranging from $(30 \%: 50 \%)$ of the maximum performance. $(14: 9)(5: 5)$

Oriented exercises: they are special exercises related to the kinetic path of kinetic skills and are developed according to scientific codified foundations and in accordance with the practical expertise in order to reach the optimum skill performance. (Procedural definition)

Kinematic Analysis: It is an analytical and mathematical description of the types of movement, and not the causes of the movement. (45:129)

\section{Research Procedures:}

1- Method: The researcher used the experimental method because of its appropriateness of the nature of the research, using the experimental design with pre and post measurements on two groups (control and experimental). 
2- research sample: research sample was selected by the intentional way from the Menofia team players under (17 years old) season (2012/2013), registered in the Egyptian Federation of Wrestling, where the research community reaches (25) wrestler, (7) wrestlers were selected to conduct exploratory studies, and (18 ) wrestlers for basic study and were divided to two equal groups, one is experimental and the other is control, (9) wrestlers for each group, and Table 1 shows the homogeneity of the research sample in the variables of (age - height - weight - training age).

\section{Table (1)}

sample homogeneity in the variables of (age-length-weight-Training age) $\mathrm{n}=\mathbf{2 5}$

\begin{tabular}{c|c||c|c|c|c|c}
\hline \hline Variables & Unit & Mean & St. Div & Median & Skewness & KURTOSIS \\
\hline \hline Age & Year & 16.62 & 0.526 & 17 & -0.757 & -1.255 \\
\hline Height & CM & 166.72 & 5.741 & 166 & -0.328 & -0.077 \\
\hline Weight & KG & 64.76 & 8.283 & 66 & 0.195 & -0.449 \\
\hline Training age & Year & 3.72 & 0.597 & 4 & 0.314 & -0.201 \\
\hline \hline
\end{tabular}

Table (1) shows that Skewness and KURTOSIS is confined between $( \pm 3)$ which shows the homogeneity of the research sample individuals in these variables and it is located under one bell curve.

Equality of the two sets of search

Table (2)

mean, standard deviation and ( $T$ test) for variables of (growth - physical - physiological - skill performance) for the two groups (experimental / control) $\quad n=18$

\begin{tabular}{|c|c|c|c|c|c|c|c|c|}
\hline \multirow{2}{*}{\multicolumn{2}{|c|}{ Variables }} & \multirow[t]{2}{*}{ unit } & \multicolumn{2}{|c|}{$\begin{array}{c}\text { Experimental } \\
\text { group } \\
\mathrm{N}=9\end{array}$} & \multicolumn{2}{|c|}{$\begin{array}{c}\text { Control group } \\
\quad \mathrm{N}=9\end{array}$} & \multirow[t]{2}{*}{ M.D } & \multirow[t]{2}{*}{ T test } \\
\hline & & & Mean & St. Div & Mean & St. Div & & \\
\hline & Age & Year & 16.78 & 0.44 & 16.44 & 0.53 & 0.33 & 1.46 \\
\hline & Length & $\mathrm{CM}$ & 166.44 & 6.84 & 168.22 & 4.71 & -1.78 & $0.642-$ \\
\hline & Weight & KG & 64.89 & 9.58 & 67.00 & 8.43 & -2.11 & 0.496 \\
\hline & Training age & $\mathrm{Sec}$ & 3,78 & 0.67 & 3.50 & 0.50 & 0.28 & 1 \\
\hline \multirow{9}{*}{ 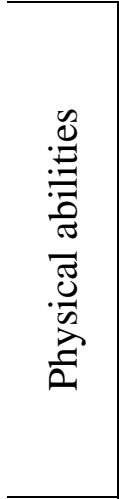 } & $\begin{array}{l}\text { Strength characterized by } \\
\text { speed }\end{array}$ & KG & 5.17 & 0.35 & 5.19 & 0.58 & 0.02 & 0.098 \\
\hline & Strength of the right fist & Pound & 95 & 7.94 & 95.89 & 6.23 & -0.89 & 0.264 \\
\hline & Strength of the left fist & Pound & 91.56 & 6.52 & 91.22 & 6.98 & 0.33 & 0.11 \\
\hline & Strength of legs & $\mathrm{KG}$ & 173.11 & 9.20 & 169.67 & 10.51 & 3.44 & 0.74 \\
\hline & Strength of back & KG & 117.60 & 1.73 & 118.22 & 1.72 & -0.56 & 0.684 \\
\hline & agility & $\mathrm{Sec}$ & 10.06 & 0.73 & 10.26 & 0.85 & -0.20 & 0.536 \\
\hline & kinetic speed & $\mathrm{Sec}$ & 1.12 & 0.11 & 1.15 & 0.14 & -0.03 & 0.414 \\
\hline & Horizontal flexibility & $\mathrm{CM}$ & 40.49 & 1.57 & 40.20 & 1.70 & 0.30 & 0.39 \\
\hline & Kinetic compatibility & $\mathrm{CM}$ & 3.44 & 1.33 & 3.33 & 1.00 & -0.11 & 0.20 \\
\hline \multirow{3}{*}{ 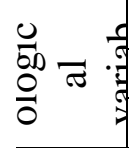 } & Pulse rate & No. & 70.22 & 3.31 & 70.67 & 3.61 & -0.44 & 0.272 \\
\hline & Anaerobic capacity & Wat & 446.44 & 42.92 & 446.56 & 41.35 & -0.11 & 0.006 \\
\hline & Forced vital capacity (Fvc) & ML & 3.39 & 0.76 & 3.36 & 0.71 & 0.03 & 0.09 \\
\hline
\end{tabular}




\begin{tabular}{c|c|c|c|c|c|c|c|c}
\hline & $\begin{array}{c}\text { Forced expiratory volume 1 } \\
\text { sec (FEV1) }\end{array}$ & ML & 2.99 & 0.57 & 2.86 & 0.66 & 0.13 & 0.45 \\
\cline { 2 - 8 } & Peak expiratory flow(PEF) & ML & 324 & 85.85 & 324 & 86.91 & 0.11 & 0.03 \\
\hline Skill performance level & Degree & 5,28 & 1,00 & 5,26 & 0,53 & 0,02 & 0,04 \\
\hline \hline
\end{tabular}

"T" value from the table at $(0.05)=2.12$

Shown from the table (2) that there are insignificant statistical differences between the two groups (control and experimental) in the variable under discussion as the values of "T" calculated is greater than the value of $(\mathrm{T})$ tabulated, which refers to the parity between groups in these variables.

\section{Tools and equipment used in data collection.}

1- Reference Survey: The researcher conducted a survey for the studies and scientific references that dealt with skill of the reverse body lift within the limits of what is available for the researcher in order to identify the kinetic path of the skill with a scientific accurate way, and it was reached to the study of (Ahmed Emara, Muhammad Al Ashram) (2006 AD) (4) entitled "Quantitative and qualitative Analysis of biomechanical characteristics of the skill of adverse middle body elevation - Repo - in the sport of Romanian wrestling" which dealt with kinetic analysis of the skill, and make use of them in developing and designing special exercises, programs and the formation of training loads.

\section{2- Questionnaire (attachment 2)}

The researcher has designed a questionnaire (attachment 2) to solicit the views of experts in the field of study variables through contact and personal interviews to give their opinion about the exercises, determine the most influential fitness elements in skill and to determine the appropriate tests for measurement and program variables, in the period from 25/06/2012 to 10/07/2012 where additions and deletions have been taken into account to suit with the experts opinion.

3- Form of data collection and recording. Attachment (3)

4- Tests used in the research. Attachment (4).

- physical tests: Strength characterized by speed (power) - maximum strength (the strength of the right and left fists - strength of legs and back muscles) - fitness flexibility - compatibility - kinetic speed.

- skill tests: the level of skill performance

- physiological tests: pulse - maximum anaerobic capacity - vital capacity.

5- Equipment used in research:- Electronic scales to measure weight to the nearest $\mathrm{kg}$ Rest meter to measure lengths to the nearest $\mathrm{cm}-$ Measuring bar to measure distances Stopwatch to measure the time per second and to the nearest 0.01 of second - Polar watches- Wrestling Mat - multi weights Wrestling Bodies - Device to measure motor speed (Video Camera, Computer and Time analysis program (Animation Shop 3) Manometer to measure fist strength - Dynamometer to measure Leg and Back Muscles Strength - GYM contains (Training devices with weights - weights bars of multiple lengths, shapes and weights - Weights pulleys of multiple weights - dumbbell of multiple weights).

\section{Training Program. Attachments (5,6,7)}

- The preparation of the proposed training program: After analysis procedures and reference survey for Arabic and foreign books, researches and studies associated with 
research variables in the field of sportive training, training of wrestling, within the limits of researcher knowledge, and meeting and contacting with experts in the field of wrestling, the researcher was able to start designing the proposed program.

- Main objective of the program: - The program aims to:

1- Raising the level of performance of some physical and physiological abilities of the wrestlers of the research sample.

2- Improving the skill performance level of the skill of the reverse body lift (speed of throwing and overthrow) as an indicator of the improvement of throwing backward by arching skills.

- Duration of the program: - 12 weeks

- Program planning: the proposed training program consists of two consecutive phases :-

The first stage: - stage of training with weights to prepare the ligaments and joints, and development of force bearing and muscle strength as establishing and preparing for ballistic resistance training for (6 weeks).

The second phase: - ballistic exercises oriented according to the kinematic analysis of skill performance of the skill of the reverse body lift (as an indicator of the skills of throwing backward by arching) for a period of (6 weeks)

\section{Foundations and criteria building the program.}

- Analysis and study of some of the training programs that have been planned previously.

- That the training program commensurate with the objectives set.

- Determine the period of application of the program

- Appropriateness of the program and its contents for the age of the selected sample, and taking into account the individual differences.

- Continuity and regularity in exercising the training program with the flexibility of the program and its ability to be modified.

- Determine the intensity and volume of exercises and periods of intra rest according to the training loads and the content and the goal of each stage of the periods of the training program and taking into account the grading in loads throughout the training program.

- Taking into account, decreasing the positive rest periods gradually with the increase of the intensity and volume of exercise used.

- Taking into account the foundations for weightlifting exercises, including a good warm-up before the start of weightlifting training then good extending and flexibility exercises after the end of the weightlifting training - determining the used weight according to the required intensity through testing the maximum weight that the user can lift at once.

\section{Foundations and standards ballistic resistance training.}

- A period of founding proceeds the ballistic exercises to improve muscular endurance and the preparation of the ligaments and joints.

- Training on ballistic resistors for (4: 8 weeks) only is preferred and then stopping for a period of (4: 8 weeks) before practicing it again because of its explosive nature that cause rapid fatigue.

- Intensity of ballistic exercises measured by the number of repetitions or performance time, and the training must be stopped when noting the slow of the movement. (44-55) 
- The need to ensure the proper functioning in accordance with the skill kinetic path with light and medium weights (30\%: 50\%) of the maximum weight that the player can bear, and at a fast rate and large kinetic extent.

- Implement every repeat as utmost repetition attempt from the start to the end and at a rate of (3: 5) repetitions only by at least ( $20 \mathrm{sec})$, followed by a rest period of (30 sec) and by a pulse of $(90 \%)$ of the maximum pulse and this is to be continued to the extent of slowing the performance speed. (44-56)

\section{Determinants of the training program}

The period of implementation of the program:-The training program is implemented in the special preparation and time before competitions period for (12 weeks) by ( 4 units) of training per week.

The program has been divided into two phases:

1. Preparation phase is (6) weeks: includes exercises with weights (two weeks to improve the ligaments and joints) and (4 weeks to establish, prepare and develop muscle strength).

2. Customization phase is (6) weeks, and includes ballistic exercises for the development of strength characterized with speed (power) and fast explosive strength.

- The total number of the program modules is 48 units. (24 units with weights and 24 units of oriented program ballistic exercises)

- Module time is $120 \mathrm{~min}$

- The total time of the program is (5760 min), which means (96 hours)

- Training methods used (Low-intensity periodic training - high-intensity periodic training - Recursive training)

- The formation of training load. (attachment 5) The researcher used ripple method during program as (3-1), (2-1) and (1-1)

- Determination of the intensity of training loads:

maximum intensity reached $(95-100 \%)$, the intensity lower than the maximum $(85-94 \%)$,

high intensity (75-84\%), medium intensity (65-74\%), and low-intensity (50-64\%)

- Rationing of training loads:

First: during Preparation phase Weightlifting training. (Attachment 6)

- The training loads in the weightlifting training were rationed using one repetition maximum for every involved muscle according to selected exercise. $(1: 193)$

- Table (4)

- Determination of repetitions according to one repetition maximum

\begin{tabular}{|c|c|c|c|c|}
\hline Load Degree & Intensity & Repetition & Sets & $\begin{array}{c}\text { Rest between } \\
\text { sets } \\
\end{array}$ \\
\hline \multirow{2}{*}{ Maximum } & $100 \%$ & 1 & 1 & \multirow{2}{*}{$1.5: 3 \mathrm{~min}$} \\
\hline & $95 \%$ & 2 & $1-3$ & \\
\hline \multirow{4}{*}{$\begin{array}{l}\text { Lower than } \\
\text { Maximum }\end{array}$} & $93 \%$ & 3 & $1-3$ & \multirow{4}{*}{$3: 4 \mathrm{~min}$} \\
\hline & $90 \%$ & 4 & $1-3$ & \\
\hline & $87 \%$ & 5 & $3-4$ & \\
\hline & $85 \%$ & 6 & $3-4$ & \\
\hline \multirow{3}{*}{ High } & $83 \%$ & 7 & $3-4$ & \multirow{3}{*}{$3: 5 \mathrm{~min}$} \\
\hline & $80 \%$ & 8 & $3-4$ & \\
\hline & $77 \%$ & 9 & $3-5$ & \\
\hline
\end{tabular}




\begin{tabular}{l|l|l|l|l}
\hline \hline & $75 \%$ & 10 & $3-5$ & \\
\hline \multirow{2}{*}{ Moderate } & $67 \%$ & 12 & $3-5$ & \multirow{2}{*}{$1.5: 3 \mathrm{~min}$} \\
\cline { 2 - 4 } & $65 \%$ & 15 & $3-5$ & \multirow{2}{*}{10} \\
\hline \hline
\end{tabular}

$(8: 121)$

Second: during Customization phase: ballistic exercises oriented.(attachment 7) The training loads in the directed exercises training were rationed using heart rate by applying the following equation:

Target Heart Rate $=$ Resting heart rate+[Training ratio $\times($ Maximum heart rate-Resting heart rate)]...... Where;

- Average age of sample $=17$ years

- Average Resting Heart Rate of sample $=70$ pulse $/ \mathrm{min}$

- Maximum Heart Rate of sample $=220-$ Age $=220-17=203$ pulse $/ \mathrm{min}$

- Heart Rate Reserve of sample = Maximum Heart Rate - Resting Heart Rate $=203-70=$ $133 \mathrm{pulse} / \mathrm{min}$

Rationing of training loads using Heart Rate (3:235)

(Maximum load)

(Load less than maximum)

(High load)

(Moderate load) percentage $95: 100 \%$ percentage $85: 94 \%$ percentage $75: 84 \%$ percentage $65: 74 \%$
Heart rate 196:203 pulse/min Heart rate 183:195 pulse/min Heart rate 182:170pulse/min Heart rate 157:168 pulse/min

Table (3)

Basis of load formation based on performance time according to Energy Production Systems

\begin{tabular}{|c|c|c|c|c|c|c|}
\hline $\begin{array}{l}\text { Energy } \\
\text { System }\end{array}$ & $\begin{array}{l}\text { Exercise } \\
\text { period }\end{array}$ & $\begin{array}{l}\text { Exercise } \\
\text { reps }\end{array}$ & $\begin{array}{l}\text { No. of } \\
\text { Sets }\end{array}$ & $\begin{array}{l}\text { No. of } \\
\text { exercise } \\
\text { reps in set }\end{array}$ & $\begin{array}{l}\text { exercise : } \\
\text { rest }\end{array}$ & Rest type \\
\hline ATP - PC & $\begin{array}{l}10 \mathrm{sec} \\
15 \mathrm{sec} \\
20 \mathrm{sec} \\
25 \mathrm{sec}\end{array}$ & $\begin{array}{l}50 \\
45 \\
40 \\
32\end{array}$ & $\begin{array}{l}5 \\
5 \\
4 \\
4\end{array}$ & $\begin{array}{l}10 \\
9 \\
10 \\
8 \\
\end{array}$ & $1: 3$ & $\begin{array}{ll}\text { active } & \text { rest } \\
\text { (walking } & \text { and } \\
\text { stretches) } & \end{array}$ \\
\hline $\begin{array}{l}\text { ATP - PC } \\
\text {, LA }\end{array}$ & $\begin{array}{l}30 \mathrm{sec} \\
40-50 \mathrm{sec} \\
60-70 \mathrm{sec} \\
80 \mathrm{sec}\end{array}$ & $\begin{array}{l}25 \\
20 \\
15 \\
10\end{array}$ & $\begin{array}{l}5 \\
4 \\
3 \\
2\end{array}$ & $\begin{array}{l}5 \\
5 \\
5 \\
5\end{array}$ & $1: 3$ & $\begin{array}{l}\text { light } \\
\text { moderate } \\
\text { exercises and } \\
\text { Jogging }\end{array}$ \\
\hline $\mathrm{LA}, \mathrm{O}_{2}$ & $\begin{array}{l}1.3-2 \mathrm{~min} \\
2.1-2.4 \mathrm{~min} \\
2.5-3 \mathrm{~min}\end{array}$ & $\begin{array}{l}8 \\
6 \\
4 \\
\end{array}$ & $\begin{array}{l}2 \\
1 \\
1\end{array}$ & $\begin{array}{l}4 \\
6 \\
4 \\
\end{array}$ & $\begin{array}{l}1: 2 \\
1: 1 \\
\end{array}$ & $\begin{array}{l}\text { light to } \\
\text { moderate } \\
\text { exercises }\end{array}$ \\
\hline
\end{tabular}

(10:91)

The foundations of selecting the exercises used in the proposed program (Attachment 7)

\section{1- during Preparation phase: (weightlifting exercises)}

Multiple weights medical balls, free weights, weightlifting exercises, and multiple gym to develop and improve the Major muscles in the body such as the abdominal muscles, back, arms, legs

2- during the Ballistic training period: 
It depended on the study of (Ahmed Amara and Mohammed Al Ashram) (2006)(4) (Attachment 9) which performed the quantitative and qualitative analysis of biomechanical characteristics of the skill of the reverse body lift for an international player to determine the technical stages of the skill and know the biomechanical characteristics of the skill stages.

Table (5)

The biomechanical characteristics of the stages of the skill of the reverse body lift (Attachment 9)

\begin{tabular}{|c|c|c|c|c|c|c|}
\hline \multicolumn{3}{|c|}{ Technical Stages } & \multirow[b]{2}{*}{$\begin{array}{l}\text { Biomechanical Characteristics of } \\
\text { the Stage }\end{array}$} & \multirow[b]{2}{*}{$\begin{array}{l}\text { Motor Sequence of } \\
\text { Stage - Separated }\end{array}$} & \multirow{2}{*}{$\begin{array}{l}\text { Motor } \\
\text { Sequence } \\
\text { of Stage - } \\
\text { Combined }\end{array}$} & \multirow[b]{2}{*}{$\begin{array}{l}\text { Position } \\
\text { distingui } \\
\text { shing } \\
\text { the stage }\end{array}$} \\
\hline & 苞 & $\begin{array}{l}\text { Objectiv } \\
\text { e }\end{array}$ & & & & \\
\hline : : $:$ : & $\stackrel{f}{\stackrel{f}{\leftrightarrows}}$ & $\begin{array}{l}\text { Reachin } \\
\mathrm{g} \text { the } \\
\text { initial } \\
\text { position }\end{array}$ & $\begin{array}{l}\text { - Starting the initial position by } \\
\text { increasing pivot area (one foot } \\
\text { backward) } \\
\text { - Increasing balance (bend knees to } \\
\text { half) }\end{array}$ & & & \\
\hline & & $\stackrel{\underbrace{\Xi}_{\Xi}}{:}$ & $\begin{array}{l}\text { - Maximum vertical distance to the } \\
\text { center of the weight of the body } \\
\text { (Stretching knees and torso) } \\
\text { - Having maximum potential } \\
\text { energy (Stretching knees) }\end{array}$ & & & \\
\hline 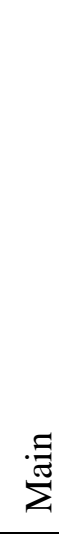 & $\begin{array}{l}\underset{J}{d} \\
\stackrel{d}{\varrho}\end{array}$ & $\begin{array}{l}\text { Drag } \\
\text { back } \\
\text { and } \\
\text { pushing } \\
\text { by } \\
\text { pelvis }\end{array}$ & $\begin{array}{l}\text {-Increase Vertical Speed (push } \\
\text { pelvis up) } \\
\text { - Increase the resultant } \\
\text { acceleration (the fall of the head } \\
\text { and torso back and down in the } \\
\text { direction of gravity) } \\
\text { - A great deal of force exerted } \\
\text { (tensile by arms in the direction of } \\
\text { the torso + lifting body on the } \\
\text { insteps) } \\
\text { - Total energy (all of the above } \\
\text { within the stage) }\end{array}$ & & & \\
\hline 丞 & $\begin{array}{l}0 \\
\frac{1}{1} \\
\stackrel{n}{=}\end{array}$ & $\begin{array}{l}\text { Turnove } \\
\mathrm{r} \text { and } \\
\text { balance } \\
\text { to } \\
\text { dominat } \\
\mathrm{e}\end{array}$ & $\begin{array}{l}\text { - Raising one shoulder and } \\
\text { lowering the other (rotation around } \\
\text { the longitudinal axis of the body) }\end{array}$ & & & \\
\hline
\end{tabular}

- Surveys:The researcher selected a random sample of the research community of (7) players outside the basic sample, and he conducted tests on them with the help of assistants, on $10 / 08 / 2012$ to $16 / 08 / 2012$.

- Study Objective

- Ensure the safety of the implementation and application of measurements and tests, validity of equipment and tools and related procedures in accordance with the conditions set for them and the suitability of the place. 
- Determine the time required for measurement and the time each player takes at each test for measurement.

- Identify the mistakes that we could make during the implementation of tests and measurements and arrange its conduct and their suitability for the age range.

- We ensure the appropriate tests to sample as well as the tools and the place of the measurements, as well as to ensure familiarity of assistants on how to conduct the tests in order to avoid measurement errors.

\section{- Scientific coefficients for tests used}

Although the physiological devices used in the research are calibrating devices in the lab, but the researcher put their results under the validity and reliability tests to ensure the accuracy of assistants during the measurement process and recording the results.

1- Test sincerity: The researcher calculated sincerity of distinction between two groups; one is not distinguished and it is outside the basic sample (senior over 20 years old ) while the other is distinguished (surveyed) and each of them consisted of (7) wrestlers.

Table (6)

Indication of the differences between the two groups (distinguished and nondistinguished) in the tests of the research $\mathrm{n} 1=\mathrm{n} 2=\mathbf{7}$

\begin{tabular}{|c|c|c|c|c|c|c|c|}
\hline & \multirow[t]{2}{*}{ Variables } & \multicolumn{2}{|c|}{$\begin{array}{c}\text { Distinguished } \\
\text { Group }\end{array}$} & \multicolumn{2}{|c|}{$\begin{array}{c}\text { Non-distinguished } \\
\text { Group }\end{array}$} & \multirow[t]{2}{*}{ M.D } & \multirow[t]{2}{*}{ T test } \\
\hline & & Mean & St.Div & Mean & St.Div & & \\
\hline \multirow{9}{*}{ 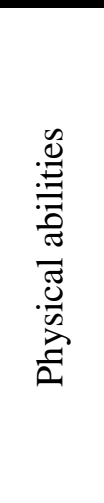 } & $\begin{array}{l}\text { Strength characterized } \\
\text { by speed }\end{array}$ & 4.31 & 0.30 & 4.83 & 502 & 0.51 & $* 2.32$ \\
\hline & $\begin{array}{l}\text { Strength of the right } \\
\text { fist }\end{array}$ & 105.29 & 2.36 & 101.00 & 3.46 & 4.29 & $* 2.33$ \\
\hline & Strength of the left fist & 94.29 & 3.15 & 89.71 & 3.45 & 4.57 & $* 2.71$ \\
\hline & Strength of legs & 183.00 & 7.85 & 170.14 & 11.57 & 12.86 & $* 2.59$ \\
\hline & Strength of back & 138.29 & 20.05 & 117.86 & 1.86 & 20.43 & $* 2.43$ \\
\hline & agility & 9.19 & 0.26 & 9.70 & .50 & 0.51 & $* 2.68$ \\
\hline & kinetic speed & 1.09 & 0.09 & 1.20 & .09 & 0.11 & $* 2.40$ \\
\hline & Horizontal flexibility & 43.94 & 3.08 & 40.48 & 1.26 & 3.46 & $* 2.21$ \\
\hline & Kinetic compatibility & 4.14 & 1.07 & 2.71 & .76 & 1.43 & $* 2.75$ \\
\hline \multirow{5}{*}{ 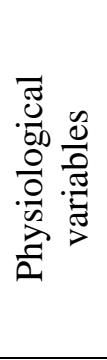 } & Pulse rate & 64.43 & 6.29 & 70.86 & 4.41 & 6.43 & $* 2.89$ \\
\hline & Anaerobic capacity & 496.29 & 27.48 & 448.71 & 32.02 & 47.57 & $* 2.21$ \\
\hline & $\begin{array}{l}\text { Forced vital capacity ( } \\
\text { Fvc) }\end{array}$ & 4.69 & 0.28 & 4.12 & .57 & 0.57 & $* 2.98$ \\
\hline & $\begin{array}{c}\text { Forced expiratory } \\
\text { volume } 1 \mathrm{sec}(\mathrm{FEV} 1)\end{array}$ & 3.45 & 0.73 & 2.52 & .24 & 0.93 & $* 2.38$ \\
\hline & $\begin{array}{c}\text { Peak expiratory } \\
\text { flow(PEF) }\end{array}$ & 425.86 & 103.63 & 321.29 & 57.84 & 104.57 & $* 3.20$ \\
\hline \multicolumn{2}{|c|}{ Skill performance level } & 5.28 & 7.36 & 1.03 & 6.11 & 1.02 & $* 1.24$ \\
\hline
\end{tabular}

" $\mathrm{T}$ " value from the table at $(0.05)=2.179$

Shown in Table (6) the presence of statistically significant differences in favor of distinguished group, which refers to the sincerity of the tests. 


\section{Tests stability}

The researcher calculated tests stability using re-testing on the surveyed sample of (7) wrestlers during 10 and11/08/2012, after a week as interval between the two applications.

Table (7)

The arithmetic mean, standard deviation and correlation coefficient between the first application and the second application of physical tests under discussion for the surveyed sample $n=(7)$

\begin{tabular}{|c|c|c|c|c|c|c|}
\hline \multirow{2}{*}{\multicolumn{2}{|c|}{ Variables }} & \multicolumn{2}{|c|}{ First application } & \multicolumn{2}{|c|}{$\begin{array}{c}\text { Second } \\
\text { application }\end{array}$} & \multirow{2}{*}{$\mathbf{R}$} \\
\hline & & Mean & $\begin{array}{l}\text { St. } \\
\text { Div }\end{array}$ & Mean & $\begin{array}{l}\text { St. } \\
\text { Div } \\
\end{array}$ & \\
\hline \multirow{9}{*}{ 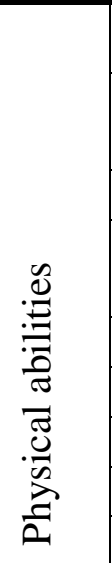 } & Strength characterized by speed & 4.83 & 502 & 4.74 & 0.5 & 0.957 \\
\hline & Strength of the right fist & 101 & 3.46 & $\begin{array}{l}100.8 \\
6\end{array}$ & 3.08 & 0.969 \\
\hline & Strength of the left fist & 89.71 & 3.45 & 90.86 & 2.91 & 0.808 \\
\hline & Strength of legs & 170.14 & 11.57 & $\begin{array}{l}171.5 \\
7\end{array}$ & 10.29 & 0.954 \\
\hline & Strength of back & 117.86 & 1.86 & 118.1 & 1.77 & 0.965 \\
\hline & agility & 9.7 & 0.5 & 9.6 & 0.56 & 0.879 \\
\hline & kinetic speed & 1.2 & 0.09 & 1.24 & 0.14 & 0.884 \\
\hline & Horizontal flexibility & 40.48 & 1.26 & 40.19 & 1.07 & 0.924 \\
\hline & Kinetic compatibility & 2.71 & 0.76 & 2.86 & 0.69 & 0.867 \\
\hline \multirow{5}{*}{ 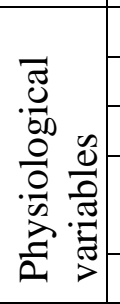 } & Pulse rate & 70.86 & 4.41 & 71 & 3.92 & 0.984 \\
\hline & Anaerobic capacity & 448.71 & 32.02 & 448.3 & 33.75 & 0.996 \\
\hline & Forced vital capacity ( Fvc) & 4.12 & 0.57 & 4.22 & 0.63 & 0.910 \\
\hline & $\begin{array}{l}\text { Forced expiratory volume } 1 \mathrm{sec} \\
\text { (FEV1) }\end{array}$ & 2.52 & 0.24 & 2.47 & 0.31 & 0.927 \\
\hline & Peak expiratory flow(PEF) & 321.29 & 57.84 & 323.1 & 57.09 & 0.997 \\
\hline \multicolumn{2}{|c|}{ Skill performance level } & 6.11 & 1.02 & 6 & 0.957 & 0.921 \\
\hline
\end{tabular}

The tabulated value of " $R$ " is $(0.754)$ at significance level $(0.05)$

As reflected in the table (7), the value of calculated "R" is greater than the tabulated "R" which indicates the stability of tests under discussion.

- Pre measurements: pre measurements were conducted for members of the research sample from 22 to 23/08/2012.

- Implementation of the program on the experimental sample: The proposed program has been implemented in the period from Saturday, 25/08/2012 to 16/11/2012.

- The control sample program: the control group received weightlifting exercises with the experimental group within the proposed program for a period of (6 weeks) and then moved to training with the team coach program and traditional training for the development of the muscle strength and even the post measurements.

- Post measurements: pre measurements were conducted from 17to 19/11/2012 under the same conditions and specifications of the pre measurements and the same place.

- Statistical processing : The researcher has used the following statistical operations in the processing of this study: 
- Mean

- Median

- KURTOSIS

- ETA $^{2}$ coefficient

- percentage of change
- standard deviation

- Skewness

- Correlation coefficient

- T test

\section{- Presentation and discussion of results}

Table (8)

Indication of differences between the two measurements (pre / post) of the experimental group and the value of "ETA ${ }^{2 "}$ and the rate of change (improvement) in the physical and physiological variables and the level of skill performance $\quad n=(9)$

\begin{tabular}{|c|c|c|c|c|c|c|c|c|c|c|}
\hline & \multirow{2}{*}{\multicolumn{2}{|c|}{ Variables }} & \multicolumn{2}{|c|}{$\begin{array}{c}\text { Pre } \\
\text { measurement } \\
\end{array}$} & \multicolumn{2}{|c|}{$\begin{array}{c}\text { Post } \\
\text { measurement }\end{array}$} & \multirow{2}{*}{ M.D } & \multirow{2}{*}{$\begin{array}{c}\text { T } \\
\text { T-test }\end{array}$} & \multirow[t]{2}{*}{ ETA $^{2}$} & \multirow{2}{*}{$\begin{array}{c}\text { Rate of } \\
\text { change }(\%)\end{array}$} \\
\hline & & & Mean & St.Div & Mean & St.Div & & & & \\
\hline \multirow{9}{*}{ 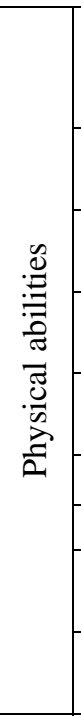 } & \multicolumn{2}{|c|}{$\begin{array}{c}\text { Strength } \\
\text { characterized by } \\
\text { speed }\end{array}$} & 5.17 & 0.35 & 4.04 & 0.22 & 1.12 & $* 6.77$ & 0.85 & $21.86 \%$ \\
\hline & \multicolumn{2}{|c|}{$\begin{array}{l}\text { Strength of the } \\
\text { right fist }\end{array}$} & 95 & 7.94 & 104.56 & 6.95 & 9.56 & $* 7.65$ & 0.88 & $10.06 \%$ \\
\hline & \multicolumn{2}{|c|}{$\begin{array}{l}\text { Strength of the left } \\
\text { fist }\end{array}$} & 91.56 & 6.52 & 100.67 & 6.61 & 9.11 & $* 4.26$ & 0.69 & $9.95 \%$ \\
\hline & \multicolumn{2}{|c|}{$\begin{array}{c}\text { Strength of the legs } \\
\text { muscles }\end{array}$} & 173.11 & 9.20 & 192.33 & 11.91 & 19.22 & * 10.44 & 0.93 & $11.10 \%$ \\
\hline & \multicolumn{2}{|c|}{$\begin{array}{l}\text { Strength of the } \\
\text { back muscles }\end{array}$} & 117.6 & 1.73 & 128.33 & 4.98 & 10.67 & * 6.187 & 0.83 & $9.12 \%$ \\
\hline & \multicolumn{2}{|c|}{ agility } & 10.06 & 0.73 & 7.57 & 0.78 & 2.49 & $* 9.72$ & 0.92 & $24.75 \%$ \\
\hline & \multicolumn{2}{|c|}{ kinetic speed } & 1.12 & 0.115 & 0.817 & 0.099 & 0.303 & $* 8.15$ & 0.89 & $241.1 \%$ \\
\hline & \multicolumn{2}{|c|}{$\begin{array}{l}\text { Horizontal } \\
\text { flexibility }\end{array}$} & 40.49 & 1.57 & 34.24 & 2.33 & 6.25 & $* 6.52$ & 0.84 & $15.44 \%$ \\
\hline & \multicolumn{2}{|c|}{$\begin{array}{c}\text { Kinetic } \\
\text { compatibility }\end{array}$} & 3.44 & 1.33 & 4.67 & 0.50 & 1.22 & $* 2.82$ & 0.50 & $35.76 \%$ \\
\hline \multirow{5}{*}{ 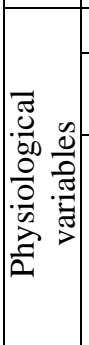 } & \multirow{2}{*}{\multicolumn{2}{|c|}{$\begin{array}{c}\text { Pulse rate } \\
\text { Anaerobic } \\
\text { maximum capacity }\end{array}$}} & 70.22 & 3.31 & 65.89 & 2.94 & 4.33 & $* 3.88$ & 0.65 & $6.18 \%$ \\
\hline & & & 446.44 & 42.92 & 539.89 & 42.07 & 93.44 & $* 8.20$ & 0.89 & $20.93 \%$ \\
\hline & \multirow{3}{*}{ 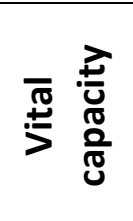 } & Fvc & 3.39 & 0.76 & 4.30 & 0.60 & 0.91 & $* 8.17$ & 0.89 & $26.84 \%$ \\
\hline & & FEV1 & 2.99 & 0.57 & 4.11 & 0.43 & 1.13 & $* 11.14$ & 0,94 & $37.46 \%$ \\
\hline & & PEF & 324 & 85.85 & 423.67 & 58,76 & 99.67 & $* 6.01$ & 0.82 & $30.76 \%$ \\
\hline \multicolumn{3}{|c|}{ Skill performance level } & 5.28 & 1 & 8,43 & 0,64 & 3,16 & $* 9,22$ & 0,91 & $59,66 \%$ \\
\hline
\end{tabular}

Tabulated value of (T) is (1.86) at a significance level of (0.05) and freedom degree of $=8$

* ETA 2 (effect strength test) and its results are estimated are as follows: -

(From zero to less than $0.3=$ weak effect $),($ From 0.3 to less than $0.5=$ medium effect $)$

$\underline{(\text { From } 0.5 \text { to one }=\text { true strong influence })}$

Table (8) shows that there are statistically significant differences between the two measurements pre and post of the experimental group in favor of the post measurement in the physical and physiological variables and the level of skill performance as the test value of (T) calculated is higher than the value of tabulated $(\mathrm{T})$ for all the variables. Results of table (8) also indicate that the value of (ETA 2) that indicates the strength of the effect of the proposed training program have ranged between (0.50: 0.94) on the physical and physiological variables and the level of skill performance of the experimental group. As well as, the rate of 
improvement ranged between (5.54\%: 59.66\%) between the measurement (pre / post) of the experimental group in the physical and physiological variables and the level of skill performance in the favor of the post measurement.

Table (9)

Indication of differences between the two measurements (pre / post) of the control group and the value of "ETA ${ }^{2 "}$ and the rate of change (improvement) in the physical and physiological variables and the level of skill performance $\quad n=(9)$

\begin{tabular}{|c|c|c|c|c|c|c|c|c|c|c|}
\hline \multirow{2}{*}{\multicolumn{3}{|c|}{ Variables }} & \multicolumn{2}{|c|}{ Pre -measurement } & \multicolumn{2}{|c|}{$\begin{array}{c}\text { Post - } \\
\text { measurement }\end{array}$} & \multirow{2}{*}{$\begin{array}{c}\text { Mean } \\
\text { Differe } \\
\text { nce }\end{array}$} & \multirow{2}{*}{$\begin{array}{c}\mathbf{T} \\
\text { T-test }\end{array}$} & \multirow{2}{*}{$\begin{array}{c}* \\
\text { ETA2 }\end{array}$} & \multirow{2}{*}{$\begin{array}{c}\begin{array}{c}\text { Rate of } \\
\text { change } \\
(\%)\end{array}\end{array}$} \\
\hline & & & Mean & St.Div & Mean & St.Div & & & & \\
\hline \multirow{9}{*}{ 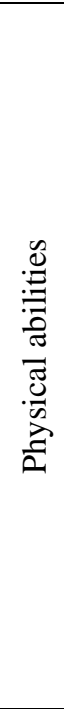 } & \multicolumn{2}{|c|}{$\begin{array}{c}\text { Strength } \\
\text { characterized by } \\
\text { speed }\end{array}$} & 5.19 & 0.58 & 4.6 & 0.7 & 0.59 & $* 2.25$ & 0.39 & $11.37 \%$ \\
\hline & \multicolumn{2}{|c|}{$\begin{array}{l}\text { Strength of the } \\
\text { right fist }\end{array}$} & 95.89 & 6.23 & 101.22 & 6.59 & 5.33 & $* 3.04$ & 0.54 & $5.56 \%$ \\
\hline & \multicolumn{2}{|c|}{$\begin{array}{c}\text { Strength of the left } \\
\text { fist }\end{array}$} & 91.22 & 6.98 & 99.67 & 2.69 & 8.44 & $* 3.66$ & 0.63 & $9.26 \%$ \\
\hline & \multicolumn{2}{|c|}{$\begin{array}{c}\text { Strength of the legs } \\
\text { muscles }\end{array}$} & 169.67 & 10.52 & 181.44 & 9.75 & 11.78 & $* 2.46$ & 0.43 & $6.94 \%$ \\
\hline & \multicolumn{2}{|c|}{$\begin{array}{c}\text { Strength of the } \\
\text { back muscles }\end{array}$} & 118.22 & 1.72 & 122.11 & 7.09 & 3.89 & $* 1.86$ & 0.3 & $3.29 \%$ \\
\hline & \multicolumn{2}{|c|}{ agility } & 10.26 & 0.85 & 9.52 & 0.71 & 0.74 & $* 2.94$ & 0.52 & $7.21 \%$ \\
\hline & \multicolumn{2}{|c|}{ kinetic speed } & 1.15 & 0.14 & 1.05 & 0.1 & 0.09 & $* 1.98$ & 0.33 & $8.70 \%$ \\
\hline & \multicolumn{2}{|c|}{$\begin{array}{l}\text { Horizontal } \\
\text { flexibility }\end{array}$} & 40.2 & 1.69 & 36.23 & 5.32 & 3.97 & $* 2.73$ & 0.48 & $9.88 \%$ \\
\hline & \multicolumn{2}{|c|}{$\begin{array}{c}\text { Kinetic } \\
\text { compatibility }\end{array}$} & 3.33 & 1 & 3.89 & 0.78 & 0.556 & $* 1.89$ & 0.31 & $16.82 \%$ \\
\hline \multirow{5}{*}{$\begin{array}{l}\overline{\mathscr{U}} \\
60 \\
0\end{array}$} & \multicolumn{2}{|c|}{ Pulse rate } & 70.67 & 3.61 & 69.11 & 3.41 & 1.56 & $* 1.94$ & 0.32 & $2.21 \%$ \\
\hline & \multicolumn{2}{|c|}{$\begin{array}{c}\text { Anaerobic } \\
\text { maximum capacity }\end{array}$} & 446.56 & 41.35 & 475.11 & 32.93 & 28.56 & $* 1.92$ & 0.32 & $6.39 \%$ \\
\hline & \multirow{3}{*}{$\begin{array}{c}\text { Vital } \\
\text { capacity }\end{array}$} & Fvc & 3.36 & 0.71 & 4 & 0.74 & 0.64 & $* 2.77$ & 0.49 & $19.05 \%$ \\
\hline & & FEV1 & 2.86 & 0.66 & 3.43 & 0.56 & 0.58 & $* 2.46$ & 0.43 & $19.93 \%$ \\
\hline & & PEF & 324 & 86.91 & 367.67 & 68.69 & 43.67 & $* 1.90$ & 0.31 & $13.48 \%$ \\
\hline \multicolumn{3}{|c|}{ Skill performance level } & 5.26 & 0.53 & 5.6 .39 & 0.74 & 1.13 & $* 2.90$ & 0.51 & $21.48 \%$ \\
\hline
\end{tabular}

Tabulated value of $(\mathrm{T})$ is (1.86) at a significance level of $(0.05)$ and freedom degree of $=8$

* ETA 2 (effect strength test) and its results are estimated are as follows: -

(From zero to less than $0.3=$ weak effect), (From 0.3 to less than $0.5=$ medium effect)

$\underline{(\text { From } 0.5 \text { to one }=\text { true strong influence })}$

Table (9) shows that there are statistically significant differences between the two measurements pre and post of the control group in favor of the post measurement in the physical and physiological variables and the level of skill performance as the test value of (T) calculated is higher than the value of tabulated $(\mathrm{T})$ for all the variables. Results of table (9) also indicate that the value of (ETA 2) that indicates the strength of the effect of the proposed training program have ranged between (0.30: 0.54) on the physical and physiological variables and the level of skill performance of the experimental group. As well as, the rate of improvement ranged between $(3.29 \%: 26.73 \%)$ between the measurement (pre / post) of the control group in the physical and physiological variables and the level of skill performance in the favor of the post measurement. 


\section{Table 10}

Indication of the differences between the two post measurements of the two groups (experimental and control) in the physical and physiological variables and the level of skill performance

$$
\mathrm{n} 1=\mathrm{n} 2=(\mathbf{9})
$$

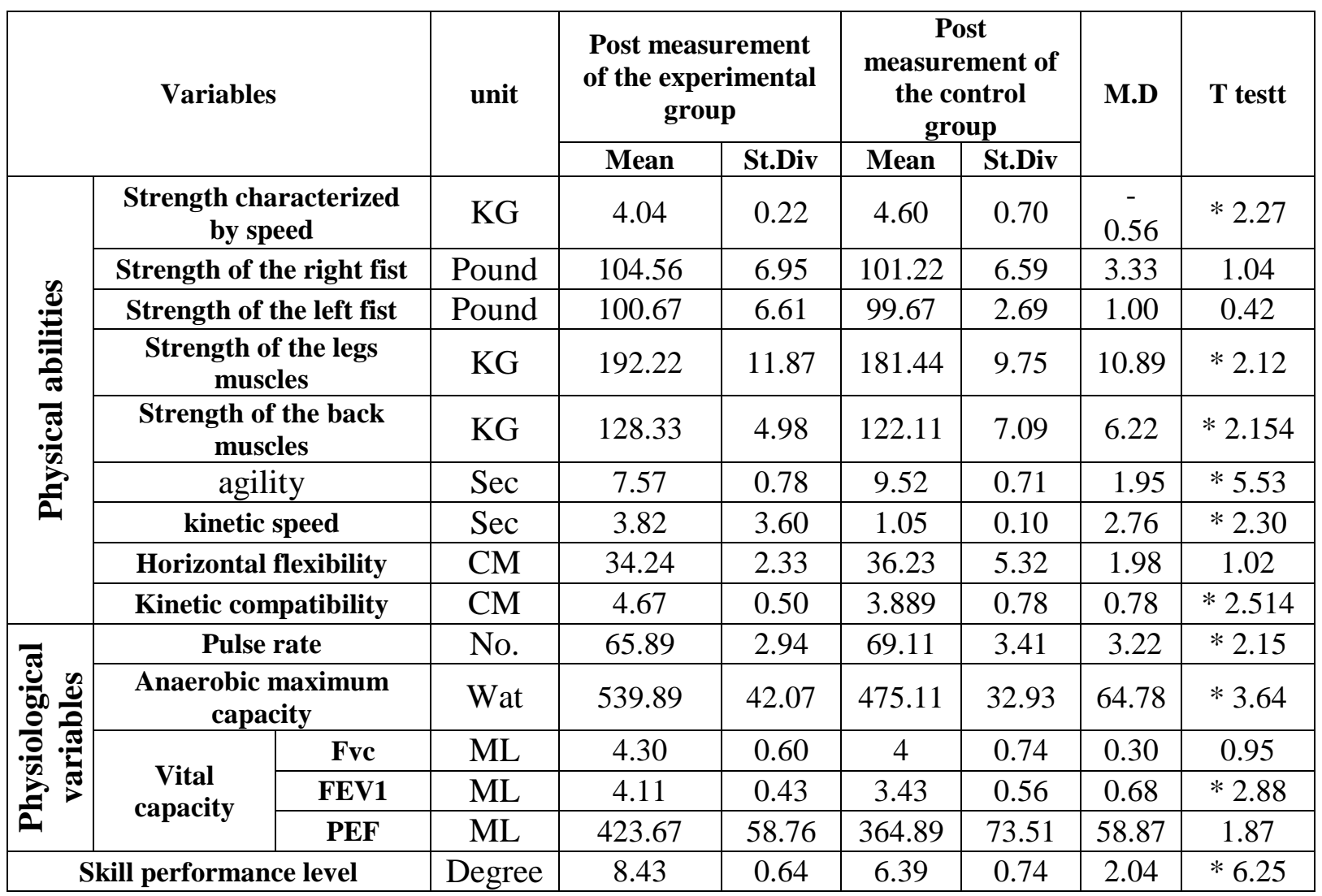

Tabulated value of $(T)$ is $(2,120)$ at a significance level of $(0.05)$ and freedom degree of $=16$

\section{* significant}

Table (10) shows that there are statistically significant differences between the two post measurements of the experimental and control group in favor of the post measurement of the experimental group in the variables (Strength characterized by speed, Strength of the legs muscles, Fitness, kinetic speed, Pulse rate ,Anaerobic maximum capacity, Forced expiratory volume in $1 \mathrm{sec}$ FEV1 and Skill performance level) where the test value of (T) calculated is higher than the value of tabulated (T) for these variables, while there is no statistical significance in the rest of the variables under research. 
Table (11)

The rate of change (improvement) in the physical and physiological variables and the level of skill performance of the two groups (experimental and control) in the post measurement

\begin{tabular}{|c|c|c|c|c|c|}
\hline \multicolumn{3}{|c|}{ Variables } & $\begin{array}{l}\text { Rate of change } \\
(\%) \text { of the } \\
\text { experimental } \\
\text { group }(n=9)\end{array}$ & $\begin{array}{c}\text { Rate of } \\
\text { change }(\%) \\
\text { of the control } \\
\text { group }(n=9)\end{array}$ & $\begin{array}{c}\text { Mean } \\
\text { different } \\
\text { (M.D) }\end{array}$ \\
\hline \multirow{9}{*}{ 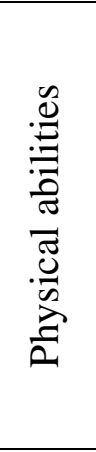 } & \multicolumn{2}{|c|}{ Strength characterized by speed } & $21.86 \%$ & $10.49 \%$ & $11.37 \%$ \\
\hline & \multicolumn{2}{|c|}{ Strength of the right fist } & $10.06 \%$ & $4.5 \%$ & $5.56 \%$ \\
\hline & \multicolumn{2}{|c|}{ Strength of the left fist } & $9.95 \%$ & $0.69 \%$ & $9.26 \%$ \\
\hline & \multicolumn{2}{|c|}{ Strength of the legs muscles } & $11.10 \%$ & $4.16 \%$ & $6.94 \%$ \\
\hline & \multicolumn{2}{|c|}{ Strength of the back muscles } & $9.12 \%$ & $5.83 \%$ & $3.29 \%$ \\
\hline & \multicolumn{2}{|c|}{ Fitness } & $24.75 \%$ & $17.54 \%$ & $7.21 \%$ \\
\hline & \multicolumn{2}{|c|}{ kinetic speed } & $241.1 \%$ & $232.4 \%$ & $8.70 \%$ \\
\hline & \multicolumn{2}{|c|}{ Horizontal flexibility } & $15.44 \%$ & $5.56 \%$ & $9.88 \%$ \\
\hline & \multicolumn{2}{|c|}{ Kinetic compatibility } & $35.76 \%$ & $18.94 \%$ & $16.82 \%$ \\
\hline \multirow{5}{*}{ 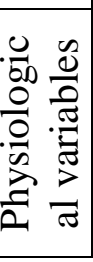 } & \multicolumn{2}{|c|}{ Pulse rate } & $6.18 \%$ & $3.97 \%$ & $2.21 \%$ \\
\hline & \multicolumn{2}{|c|}{ Anaerobic maximum capacity } & $20.93 \%$ & $14.54 \%$ & $6.39 \%$ \\
\hline & \multirow{3}{*}{ Vital capacity } & Fve & $26.84 \%$ & $7.79 \%$ & $19.05 \%$ \\
\hline & & FEV1 & $37.46 \%$ & $17.53 \%$ & $19.93 \%$ \\
\hline & & PEF & $30.76 \%$ & $17.28 \%$ & $13.48 \%$ \\
\hline \multicolumn{3}{|c|}{ Skill performance level } & $59.66 \%$ & $21.48 \%$ & $38.18 \%$ \\
\hline
\end{tabular}

The results of table (11) refers to the rate of change (improvement) in the physical and physiological variables and the level of skill performance of the two groups (experimental and control) in the post measurement.

\section{Discussing the results}

In the light of the previous presentation of the findings of the researcher, in the framework of the objectives and hypotheses of the research, being guided by the results of the previous studies and what is stipulated in the scientific references, the researcher starts to discuss those results as follows.

Table (8) shows that there are statistically significant differences between the two measurements (pre /post) of the experimental group in the physical variables of tests of strength characterized by speed and strength (the strength of the right fist and the strength of the left fist and strength of the two legs muscles and the strength of the back muscles), fitness, kinetic speed, horizontal flexibility and kinetic compatibility, and these differences were in favor of the post measurement as the calculated value of (T) of the experimental group ranged between (6.77), (7.65) , (4:26), (10:44), (6:19), (9.72), (8.15) / (6.52), (2.82), respectively, as well as it is evidenced that there are statistically significant differences in the physiological variables for measurements of pulse rate, the anaerobic maximum capacity, vital capacity 
FVC, forced expiratory volume in one second FEV1 and the volume of the maximum exhalation PEF. These differences were in favor of the post measurement where the calculated value of $(T)$ of the experimental group ranged between (3.88), (8:20), (8:17), $(11: 14),(6: 01)$, as well as, it is evidenced that there are statistically significant differences in the level of skill performance test and these differences were in favor of the post measurement where the calculated value of (T) of the experimental group was (9.22) and all these values are greater than the tabulated value of "T" which is equal to the value of (1.86) at a freedom degree of (8) which indicates that the proposed training program has a strong effect on the physical and physiological variables under research and the level of skill performance.

As well as, table (8) shows that the value of "ETA ${ }^{2}$ " coefficient (the power of the effect of the program) ranged between $(0.50,0.94)$, and it is from $(0.5$ and above), which indicates that the proposed training program has a major effect power and the exercises developed by researcher (in which the muscle work resembles the skill performance requirements and at the same kinetic path) were effective on the development of physical and physiological variables under research and the level of skill performance.

These findings are supported by the rate of improvement where the results of table (8) refer to the rate of improvement between the two measurements (pre / post) of the experimental group in the physical variables under research in favor of the post measurement where the rate of improvement in the strength characterized by speed reaches $(21.06 \%)$, the strength of the right fist reached $(10.06 \%)$, the strength of the left fist reached $(9.95 \%)$, the strength of the legs muscles reached $(11.10 \%)$, the strength of the back muscles reached $(9.12 \%)$, Fitness reached $(24.75 \%)$, the kinetic speed reached $(27.05 \%)$, the horizontal flexibility reached $(15.44 \%)$ and the kinetic compatibility reached (35.76\%), as well as the results of table ( 8) refers to the rate of improvement between the two measurements (pre / post) of the experimental group in physiological variables under research in favor of the post measurement where the improvement rate in measurements of pulse rate reached $(5.54 \%)$, the anaerobic maximum capacity reached $(20.93 \%)$, the anaerobic maximum capacity reached $(26.84 \%)$, forced expiratory volume in one second FEV1 reached $(37.46 \%)$ and the volume of the maximum exhalation PEF reached (30.76\%)

As well as, the results of table (8) refer to the rate of improvement between the two measurements (pre / post) of the experimental group in the level of skill performance under research in favor of the post measurement where the improvement rate reached $(59.66 \%)$. This indicates that the proposed training program using ballistic exercises oriented according to the kinematic analysis which its performance is characterized by the full speed by using weights of mild to moderate (30\%: 50\%) of the maximum weight, as well as the use of medical balls, weightlifting balls and pillars led to improve the muscle tone, the explosive ability of the working muscles, increasing the physical efficiency, and improving the physiological capacity under research and the level of skill performance for the skill of the reverse body lift as an indicator of the skills of throwing backward by arching.

Garber and others "Markus Garber et al" (2007 AD) indicated that the training with the rapid explosive manner (ballistic) increases the speed of kinetic performance, as the exercises used in this method of resistance exercises, medical balls and push weightlifting balls develop all of the speed, the explosive ability and Fitness, and lead to a better kinetic performance. (27 : 25) 
The researcher believes that the rapid and explosive exercises performed by the players at a pulse rate of above $90 \%$ of the maximum pulse led to the improvement of cardiac status, maximum anaerobic capacity, increase the strength of respiratory muscles and thus vital capacity variables.

This is in line with Mr. Abdel Maksoud (1992 AD) where he stated that the high-intensity explosive exercises improve the special endurance and contribute in a targeted and multieffect way to improve the organizational capacity of the heart and the two systems of (respiratory and circulatory). (7:181)

As well as, Table (9) shows that there are statistically significant differences between the two measurements (pre / post) of the control group in physical variables of the tests of strength characterized by speed and strength (the strength of his right fist and the strength of the left fist and the strength of the two legs muscles and the strength of the back muscles), fitness, kinetic speed, horizontal flexibility and kinetic compatibility and these differences were in favor of the post measurement where the calculated value of $(t)$ for the control group ranged between (2.25), (3.04) (3.66) (2.46) (1.86) (2.94) (1.98) (2.73) (1.89) consecutively. As well as it is evidenced that there are statistically significant differences in the physiological variables of the measurements of pulse rates, the anaerobic maximum capacity, vital capacity FVC, forced expiratory volume in one second FEV1 and the volume of the maximum exhalation PEF. These differences were in favor of the post measurement where the calculated value of $(t)$ of the control group ranged between (1.94), (1.92), (2.77), (2.46), (1.90), as well as it is evidenced that there are statistically significant differences in the level of skill performance test and these differences were in favor of the post measurement where the calculated value of $(t)$ of the control group was (2.90) and all these values are higher than the tabulated value of "T" which is equal to the value of (1.86) at a freedom degree of (8).

As well as, Table (9) shows that the value of "ETA 2" coefficient (the power of the effect of the program) ranged between $(0.30,0.54)$ as well as the rate of improvement between the two measurements (pre /post) of the control group in the physical variables under research in favor of the post measurement where the improvement rate in the strength characterized by speed reached $(11.37 \%)$, the strength of the right fist reached $(5.56 \%)$, the strength of the left fist reached $(9.26 \%)$, the strength of the two legs muscles reached $(6.94 \%)$, the strength of the back muscles reached (3.29\%), Fitness reached $(7.21 \%)$, the kinetic speed reached $(8.70 \%)$, the horizontal flexibility reached $(9.88 \%)$ and the kinetic compatibility reached $(16.82 \%)$, as well as the results of table (9) refer to the rate of improvement between the two measurements (pre / post) of the control group in the physiological variables under research in favor of the post measurement where the improvement rate in measurements of pulse rate reached $(2.21 \%)$, maximum anaerobic capacity reached $(6.39 \%)$, vital capacity FVC reached (19.05\%), forced expiratory volume in the first second FEV1 reached (19.93\%) and the volume of the maximum exhalation PEF reached (13.48\%), as well as the results of table (9) refer to the rate of improvement between the two measurements (pre / post) in favor of the post measurement which the improvement rate reached $(21.48 \%)$ which indicates that the traditional training program has led to the development of the physical and physiological variables under research and the level of skill performance.

Researcher attributes these differences and this progress to that, the traditional training program has led to improvement in the variables under research for the control group because of the regularity of the players, their commitment in training and repetition of performing skills, which in turn led to the upgrading of the variables under research. 
As well as, Table (10) shows that there are statistically significant differences between the two measurements (post) of the experimental group and the control group in the physical variables of the tests of strength characterized by speed and strength (the strength of the two legs muscles and the strength of the back muscles), fitness, kinetic speed and kinetic compatibility and that these differences were in favor of the post measurement of the experimental group where the calculated value of $(\mathrm{T})$ ranged between $(2: 27),(2: 12),(2: 15)$, (5:53), (2:30), (2:51), respectively.

As well as, it is evidenced that there are statistically significant differences in the physiological variables of the measurements of pulse rate, maximum anaerobic capacity and forced expiratory volume in one second FEV1. These differences were in favor of the post experimental group where the calculated value of $(\mathrm{T})$ ranged between $(2.15),(3.64),(2.88)$.

As well as, it is evidenced that there are statistically significant differences in the level of skill performance test and that these differences were in favor of the post measurement of the experimental group where the calculated value of (T) was (6.25) and all these values are greater than the tabulated value of " $\mathrm{T}$ " which is equal to the value of (2.12) at a freedom degree of (16 ) which indicates that the proposed Training Program has affected effectively on some physical and physiological variables under research and the level of skill performance.

While there are no statistically significant differences in variables of (the strength of the right fist, the strength of the left fist and the horizontal flexibility) as well as (the vital capacity FVC and the volume of the maximum expiratory PEF), but there is a clear improvement rate in the direction of the post measurement of experimental group in these variables where Table (11) shows the average differences between the improvement rates for the two measurements (post) of the experimental group and the control group which demonstrates the difference between the rate of improvement that occurred in level between the proposed program and traditional program, in physical variables, the average difference between the improvement rates of strength characterized by speed reached $(10.49 \%)$, the strength of the right fist reached $(4.5 \%)$, the strength of the left fist reached $(0.69 \%)$, the strength of the two legs reached $(4.16 \%)$, the strength of the back muscles reached $(5.83 \%)$, Fitness reached (17.54\%), the kinetic speed reached (232.4\%), the horizontal flexibility reached $(5.56 \%)$ and kinetic compatibility reached (18.94\%), and the physiological variables, the average difference in the improvement rates in the measurements of pulse rate reached $(3.97 \%)$, the maximum anaerobic capacity reached (14.54\%), Vital Capacity FVC reached (7.79\%), forced expiratory volume in the first second FEV1 reached $(17.53 \%)$, the volume of the maximum exhalation PEF reached (17.28\%) and in the level of skill performance, the average difference in the rates of improvement reached $(38.18 \%)$.

The researcher believes that these differences and the improvement rates of the experimental group are due to the proposed program for ballistic training oriented that applied to the experimental group which contains a special training for individuals and doubles, designed by a scientific manner in the same kinetic path to the skills of throwing backward by arching, " Michael $\mathrm{H}$ stone in (1998 AD) mentioned that the rapid ballistic exercises increase the explosive power and the speed of kinetic performance which addresses the lack of speed in the muscle ability exercises. $(28: 25)$

These findings are consistent with the study of all of Ali Talat in (2003 AD) (9), Olsen PD1. Hopkins WG in (2003 AD) (38), Mustafa Abdel Baqi in (2005 AD) (35), Robert and 
others in (2006 AD) (40), Mohamed Talaat, Joseph Nagy in (2009 AD) (33) (Mahmoud El Maghawry Al Sayed in (2012 AD) (26)

\section{Conclusions}

In light of the objectives and the nature of this study, in the limits of the research sample and the approach used, the reality of the data accruing to the researcher and the results of the statistical analysis, the researcher reached the following conclusions: -

1. Ballistic exercises have an effective effect in the development of some of the physical variables associated with the skill of the reverse body lift (such as the muscle ability, fitness, kinetic speed and kinetic compatibility).

2. Ballistic exercises have an effective effect in the development of some of the physiological variables of wrestlers such as pulse rate, the maximum anaerobic capacity, the forced expiratory volume in the first second FEV1, and the size of the maximum exhalation PEF.

3. Ballistic exercises have a positive effect in raising and improving the level of skill performance of the skill of the reverse body lift (as an indicator of the skills of throwing backward by arching) for the wrestlers.

\section{Recommendations}

Within the limits included by the study of procedures and the results concluded, the researcher recommends the following: -

1- Interest in ballistic exercises for the development of the physical capabilities of wrestlers according to scientific principles to increase the ability to efficiently conflict during the games.

2- Interest in ballistic exercises oriented in the direction of the kinetic pathways of the various wrestling skills.

3- The need to design similar programs for various ages.

4- Interest in kinematic analysis of skills to determine their kinetic paths, which facilitates and directs the training process.

5- Interest in refining the coaches through training courses, and introducing the modern training methods to the coaches.

\section{References}

1. Abdul Aziz Al nimr, Nariman al-Khatib(2005):"muscle strength and the design of strength programs and planning training season, Alsatzh Sports Book, Giza.

2. Abdul Rahman Zaher in (2000 AD): Physiology of competitions, bounce and jump, Book Center for Publishing, Cairo.

3. Abu El Ela Ahmed Abdel-Fattah, Ahmed Nasreddin (2003) Fitness Physiology, Dar of the Arab Thought, Cairo.

4. Ahmed Abdul Hamid Ali Amara, Mohammed Nabawy Al Ashram (2006); " quantitative and qualitative analysis of the bio mechanic characteristics of waist reverse grab skill in the Roman wrestling, theories and applications - specialized scientific journal 
in Physical Education and Sports Science - Faculty of Physical Education for Boys Alexandria University.

5. Ahmed Farooq Khalaf in (2003 AD): "The effect of ballistic training program on some physical and skill variables of basketball players", published research, the scientific journal of Physical Education and Sports, Faculty of Physical Education for Boys, Helwan University.

6. Ahmed Mohamed Gouda in (2009 AD): "The effect of the use of bliometric training for the arms on the development of kinetic speed for boxers" Master Thesis, unpublished, Faculty of Physical Education for Boys, Tanta University.

7. Al Sayed Abdel Maksoud in (1992 AD): sportive training theories - training and physiology of endurance, Free Young Printing House, Cairo.

8. Ali Fahmy Beik and others. (2009) Recent trends in sports training "theories and applications," Part III, version 1, Knowledge facility, Alexandria.

9. Ali Mohammed Talat in (2003 AD): "The effect of the use of ballistic resistance training on some physical and skill variables of basketball players", Master Thesis, Faculty of Physical Education for Boys, Helwan University.

10. Amr Allah Ahmed Al Basati in (1998 AD): principles, rules and applications of sportive training, knowledge facility, Alexandria.

11. Aweys Ali Jabali(2000) sports training between theory and training, Dar MGS

12. Bastawisi Ahmed Bastawisi in (1999 AD): Principles and theories of sportive training, Arab Thought House, Cairo.

13. Christian (2006): continuum training understanding various strength training.

14. Edmund Burke (2001): Ballistic Training for Explosive Results, Human Kinetics Publishers, United States of America.

15. Ehab Hamid Alprairie, Massad Hassan Mohamed (2008) The impact of the use of composite training on the development of muscle power and effectiveness of the performance of the skill of reverse waist grab for wrestlers, Tenth International Scientific Conference Sciences Physical Education and Sports, Faculty of Physical Education for Boys, Alexandria University.

16. Ehab Mohamed Fawzy Al Badawi(2004), the strategy for training of back throw with the back facing (the back center) through kinematic analysis, published research, theories and applications magazine, No. 53, Faculty of Physical Education for Boys, Alexandria University.

17. Essam El-Din Abdul Khaliq(2003) sports training theories and applications, ed. 13, Knowledge House, Cairo.

18. Foctours,I. G (2000): Evaluation of Plyometric exercise training weigh vuming and their combination on vertical Jumping performance and leg strength .J of strength and conditioning searth (14) (4) (470-470).

19. Gary, Moran, George, \& Mc Glynn (1997): Cross Training for Sports, Human Kinetics Publisher, United States of America.

20. Hamdi Abdo Abdel Wahed Asim in (1996 AD): "The effect of the proposed training program for the adaptation of some anaerobic energy enzymes ", $\mathrm{PhD}$ thesis, unpublished, Physical Education for Boys boys, Helwan University.

21. Hammett, J.B., Hey, W.T.( 2003); Neuromuscular adaptation to short-term (4 weeks) ballistic training in trained high school athletes. Journal of Strength and Conditioning Research 17:556-560,

22. http://www.en.wikipedia.org/wiki/Ballistic-of-a-poylomitireik-Training.

23. http://www.livestrong.com/article/531917-definition-of-a-ballistic-exercise/\#ixzz22 gjqPB1m. 
24. Ibrahim Ahmed Gazar (1998): kinematic analysis of the performance of bridge skill in wrestling, the first volume of the Scientific Research Conference on Sport and the development of the Arab community and the requirements of the twenty-first century, the Faculty of Physical Education for Girls in Al jazeera, Helwan University.

25. Ibrahim Ahmed Gazar (2001) : biomechanical analysis of the performance of skill back Throw (front center), the scientific journal of the Research and Studies volume II, Faculty of Physical Education in Port Said, Suez Canal University.

26. Ibrahim Fawzi Mustafa(1999):contribution some kinematic characteristics and special physical attributes on performance skills of back throw in wrestling, unpublished Master Thesis, Faculty of Physical Education in Port Said, Suez Canal University.

27. Kenny Croxdale (2005): Going Ballistic-More Speed/Power training Forum.

28. Mahmoud Al Maghawry Al Sayed in (2012 AD): "Ballistic training effect on the performance of some judo skills of Beginners" unpublished Master thesis, Faculty of Physical Education, Zagazig University.

29. Markus Gruber, Stefanie B.H Gruber, Wolfing Taube Martin Schubert (2007): Differential effects of Ballistic versus sensorimotor training on rate of force development and neural activation in humans, journal of strength conditioning research vol $21, \mathrm{P} \mathrm{P}$ $274-282$, February, .

30. Michael H stone, Stevens, Margaret $\mathbf{E}$ stone , brain $\mathrm{K}$ schilling and Kyle $\mathbf{C}$ pierce (1998): athletic performance development, strength and conditioning, volume 20 number , December ,

31. Mohamed Reda El Rouby(2005) principles of training in the sport of wrestling, Mahi printings, Alexandria, version 1.

32. Mohamed Sobhi Abdul Hamid in (1996 AD): the biology of the sport, Pansee House for printing, Zagazig.

33. Mohamed Talaat Abu Al-Maati, Joseph Nagy Adib in (2009AD): " comparative study of the effect of the use of different types of exercises (weightlifting, Beliometric, ballistic) on the development of muscular power of the arms and the level of skill performance of hockey players and table tennis", published research, Journal of Physical Sciences and Sports, Faculty of Physical Education in Sadat, Menoufia University.

34. Mohammad Hassan Allawi in (1994 AD): science of sportive training, T 13, Knowledge House, Cairo.

35. Mohammad Hassan Allawi, Abu Ela Abdel Fattah in (1990 AD): Physiology of sportive training - Arab Thought House.

36. Mussad Ali Mahmoud in (1987 AD): theoretical and practical bases of Romanian and free wrestling, Zagazig.

37. Mustafa Abdel Baqi Hashim in (2005 AD): a comparative study of the effect of the use of bliometric training method and ballistic training on some physical and skill variables of basketball players, unpublished Master Thesis, Faculty of Physical Education, Helwan University.

38. Nabil Hosni El Shourbagy(2008) the impact of the use of certain muscle power development methods on the effectiveness of the performance of the waist reverse grab skill for wrestlers, tenth International Scientific Conference of Sciences physical education and sport, Faculty of Physical Education for Boys, Alexandria University.

39. Newton, R.U., Kraemer, W.J., Hakkinen, K(1999).; Effects of ballistic training on preseason preparation of elite volleyball players. Medicine \& Science in Sports \& Exercise 31:323-330. 
40. Olsen PD1, Hopkins WG (2003). The effect of attempted ballistic training on the force and speed of movements. . Journal of strength and conditioning research / National Strength \& Conditioning Association. May.

41. Paul, J. and K. Duane, (1999): Basic of biomechanics Leisure Press.

42. Robert .U (2006): four week of optimal load ballistic resistance training at the end of season attenuates defining jump performance of woman volley ball player. Journal of strength and conditioning research / National Strength \& Conditioning Association.nov2006

43. Scott \& Edward (1994): exercise physiology theory and application of fitness and performance, 2nded. wmc, bro communication inc. U.S.A.

44. Sharif Mahrous Mohammed in (2005 AD): " comparative study of the effect of beliometric training with weights on the development of muscle power and the level of performance of overwhelming striking skill of volleyball beginners," Master Thesis, unpublished, Faculty of Physical Education, University of Tanta.

45. Talha Hossam El-Din (1998) Applied Movement Science, Part I, version 1,book publishing center.

46. Winchester, Jason B; McBride, Jeffrey M; Maher, Margaret A; Mikat, Richard P; Allen, Brian K; Kline, Dennis E; McGuigan, Michael R "Eight Weeks of Ballistic Exercise Improves Power Independently of Changes in Strength and Muscle Fiber Type Expression" Journal of Strength and Conditioning Research November 2008-Vol. 22 Issue 6: pp 1728-1734 